\title{
Experimental Investigation of Nickel Electrodeposits Brightness in the Presence of Surfactants: Modeling, Optimization and Polarization Studies
}

\author{
I. Djaghout, A.M. Affoune, ${ }^{*}$ M.L. Chelaghmia and M. Bendjaballah \\ Laboratoire d'Analyses Industrielles et Génie des Matériaux, Département de Génie des Procédés, \\ Faculté des Sciences et de la Technologie, Université 8 Mai 1945 Guelma, BP 401, Guelma \\ 24000, Algeria
}

Received 18 March 2015; accepted 28 August 2015

\begin{abstract}
Nickel coatings were obtained from Watts bath containing sodium dodecyl sulfate (SDS) or polyvinylpyrrolidone (PVP) surfactants by direct current plating. The influence of electrolysis parameters, temperature, current density, concentration of surfactants and $\mathrm{pH}$ on the nickel deposits brightness is investigated through a multiple linear regression model with interaction. The models obtained fitted very well the experimental data. ANOVA statistical analysis shows that all design factors are significant, and the brightness of nickel deposits obtained from bath containing PVP is more sensitive to the changes in the factors levels. The electrochemical behaviour of baths was discussed; the results revealed an inhibitive effect exerted by both SDS and PVP. We have also found that the brightness and the inhibition are well linked and directly proportional. In addition, the corrosion resistance of the nickel coatings was slightly improved, especially with PVP. Finally, the optimization analysis showed that PVP could efficiently and eco-friendly substitute SDS as an additive of nickel electroplating.
\end{abstract}

Keywords: Nickel electrodeposition; surfactants; brightness; experimental design; cyclic voltammetry.

\section{Introduction}

Nickel electrodeposition has attracted great interest these decades and became one popular surface treatment technology. Nickel coatings can be produced from a variety of electrolytes; the Watts bath is the basis for most decorative nickel

\footnotetext{
* Corresponding author. E-mail address: affoune2@yahoo.fr.
} 
plating solutions $[1,2]$. It has several advantages such as inexpensive compared to sulfamate bath, less aggressive for the work equipment than chloride bath, and deposits obtained have lower internal stress than those obtained from chloride bath. Properties of nickel deposits can be improved by addition of special organic compounds to the baths, like surfactants, refiners, brighteners, and levelling agents [3].

Surfactants reduce surface tension of the cathode which facilitates the removal of hydrogen by reducing the size of the bubbles, and consequently reduces the risk of pitting, thereby improving the quality of the deposit. Among many surfactants varieties, sodium dodecyl sulfate (SDS) is the most used in the electrodeposition of nickel [4-7]. In addition to its role of wettability, several authors have studied its influence on the morphology and the brightness of nickel coatings [4, 5], electrochemical properties of zinc [8] and the stress of electroplated copper [9]. Nevertheless, this additive presents the disadvantage of incorporating sulphur in coatings. While the presence of sulphur in the nickel coatings enhances the superplasticity [10] and improves the microhardness[11], its incorporation is detrimental regarding the corrosion resistance because it promotes a localized corrosion [12]. Besides, the sulphur causes catastrophic embrittlement at elevated temperature as low as $200{ }^{\circ} \mathrm{C}$ [11] and deteriorates the colour of deposits when it exceeds certain limits [13]. Another downside of SDS is its toxicity which may cause environmental problems. In the aim to avoid the presence of sulphur and the toxicity of SDS, we are interested in finding a surfactant substitute. Polyvinylpyrrolidone (PVP) is a famous macromolecule surfactant with many advantages such as low toxicity, biocompatibility, high surface activity, and strong adsorption ability [14]. Up to now, PVP has brought substantial interest and has been widely used in different fields, such as anticorrosion [15-17], chemical deposition [18, 19] and electrodeposition [20-23]. PVP was used as a wetting agent and a refiner in plating baths of $\mathrm{ZnO}$ [20] and $\mathrm{PbO}_{2}$ [21]. Recently, in a comparative study between five additives [22], the PVP is found to be the best additive which decreased grain size of the copper powder to a minimum threshold. To the best of our knowledge, a very few studies have been dedicated to the study of PVP effect on nickel electrodeposition [24]. Furthermore, and unlike SDS, no report has been published on the effect of PVP on the brightness of nickel electrodeposition.

The study of the electrolysis parameters effects on the performance of nickel electroplating was the subject of different investigations. Most of these works were made by the conventional methodology [25-27], wherein one factor varies while others are set at constant levels. These traditional methods often ignore the effects of interaction between factors, and lead to less accurate optimal values. To overcome this problem, experimental design methods have been used; these latter serve to optimize the organization of experiments in order to minimize the time, cost and increase reliability [28-31]. While response surface methodology (RSM) is one of the most used experimental design methods, only a very few works [32] used it to study the electrodeposition of pure nickel.

In this work, a comparative study on the effect of electrolysis parameters on the nickel deposits brightness in the presence of SDS and PVP was achieved. Results 
were analyzed using response surface methodology via full factorial design modelling. A complementary polarization study was also conducted to evaluate the electrochemical behaviour of baths and deposits.

\section{Experimental}

\section{Electrodeposition}

Nickel coatings were prepared by direct-current galvanostatic deposition onto copper substrate $(60 \mathrm{~mm} \times 20 \mathrm{~mm})$, from a conventional Watts bath composed of $250 \mathrm{~g} \mathrm{~L}^{-1} \mathrm{NiSO}_{4} .6 \mathrm{H}_{2} \mathrm{O}, 45 \mathrm{~g} \mathrm{~L}^{-1} \mathrm{NiCl}_{2} .6 \mathrm{H}_{2} \mathrm{O}$, and $40 \mathrm{~g} \mathrm{~L}^{-1} \mathrm{H}_{3} \mathrm{BO}_{3}$. An appropriated amount of sodium dodecyl sulfate and polyvinylpyrrolidone was added to the electrolytic bath and dilute solutions of sodium hydroxide $(\mathrm{NaOH})$ and sulphuric acid $\left(\mathrm{H}_{2} \mathrm{SO}_{4}\right)$ were used for $\mathrm{pH}$ adjustments. All solutions were prepared with analytical grade chemicals and ultrapure water. Prior to nickel electrodeposition, the substrate surface was subjected to mechanical treatment with metallurgical papers of 800, 1200 and 2000 grits, then cleaned with $1.0 \mathrm{M}$ $\mathrm{HCl}$ and rinsed by ultrapure water. All the electrodeposition experiments were conducted for $120 \mathrm{~s}$ by applying current from an AX 501 METRIX regulated power supplier (0-30 V/2.5 A). After electrolysis, the samples were removed from the cell and thoroughly washed with ultrapure water and dried.

\section{Brightness measurements}

The brightness of the metallic deposits was evaluated using a BYK-Gardner micro-gloss meter with an extended beam white light. Sample surface was carefully cleaned before measurement, in order to obtain consistent results. The calibration was performed automatically by means of a highly polished black standard integrated in the gloss meter. Measurements were performed in three replicates for each coating, in which the mean was considered the final value.

\section{Kinetics study}

Cyclic voltammetry experiments were carried out in a conventional threeelectrode glass cell using an EG \& G Princeton Applied Research potentiostat/galvanostat model 273A controlled by Power Suite software. A copper substrate and platinum wire of $0.5 \mathrm{~mm}$ diameter were used as working and auxiliary electrodes, respectively, and a saturated calomel electrode (SCE) served as the reference electrode. Voltammograms were obtained in the potential range between $-1200 \mathrm{mV}$ and $+50 \mathrm{mV}$, with a scan rate of $20 \mathrm{mVs}^{-1}$. The corrosion resistance of the nickel coatings was studied in $3.5 \% \mathrm{NaCl}$. Prior to experiments, samples were immersed in solution for $30 \mathrm{~min}$, at room temperature. The polarization curves were performed from -500 to $0 \mathrm{mV}$ at scan rate of $5 \mathrm{mVs}^{-1}$, using an EG \& G Princeton Applied Research potentiostat/galvanostat model VersaSTAT 3 controlled by VersaStudio software. 


\section{Results and discussion}

\section{Statistical study}

In a full factorial design, we combine all the factors in a common experience design in which each factor takes two levels, low and high levels, symbolized by $(-1)$ and $(+1)$, respectively.

The relationship between the input, called electrolysis parameters, temperature $(T)$, current density $(i)$, concentration of surfactant $(C)$ and $(p H)$ of the solution, and the output $\widehat{\mathrm{Y}}$ defined as a nickel deposits brightness $(B r)$ is given as:

$$
\widehat{\mathrm{Y}}=\mathbb{F}(T, i, C, p H)
$$

where $\mathbb{P}$ is the response function.

The approximation of $\widehat{Y}$ was established by multiple linear regression model with interaction. The coded mathematical model can be given by:

$$
\overline{\mathrm{Y}}=\mathrm{b}_{0}+\Sigma_{1}^{\mathrm{n}} b_{i} X_{i}+\Sigma_{1}^{\mathrm{n}} b_{i j} X_{i} X_{j}
$$

where $b_{0}$ is the free term of the regression equation, $b_{i}$ coefficient represents the effect of the factors $X_{\overline{2}}$, and $b_{i j}$ is the coefficient of regression which represents the effects of interactions of factors $X_{i}$ and $X_{j}$. Design and statistical analysis were performed using Design Expert software, version 9.0.3 (Stat-Ease, USA).

\section{Modelling for the nickel deposits brightness}

The choice of the studied factors levels is based on data from industrial applications and research works [2, 4, 22]. Table 1 summarizes the factors notations, their actual and reduced values. Based on two-level four factor full factorial design $\left(2^{4}\right)$, a total number of 16 trials were carried out for each surfactant. The design matrix and the corresponding experimental responses of the brightness are given in Table 2.

Table 1. Factors and levels for the full factorial design.

\begin{tabular}{|c|c|c|c|}
\hline \multirow{2}{*}{ Design factors } & \multirow{2}{*}{ Symbol } & \multicolumn{2}{|c|}{ Levels } \\
\cline { 3 - 4 } & & $\mathbf{- 1}$ & $\mathbf{+ 1}$ \\
\hline Temperature $\left({ }^{\circ} \mathrm{C}\right)$ & $\mathrm{T}$ & 45 & 60 \\
\hline Current density $\left(\mathrm{A} \mathrm{dm}^{-2}\right)$ & $\mathrm{i}$ & 20 & 10 \\
\hline \multirow{2}{*}{ Surfactant concentration $\left(\mathrm{mg} \mathrm{L}^{-1}\right)$} & $\mathrm{C}_{\mathrm{SDS}}$ & 20 & 60 \\
\cline { 2 - 4 } & $\mathrm{C}_{\mathrm{PVP}}$ & 20 & 4000 \\
\hline Acidity of the solution & $\mathrm{pH}$ & 2.5 & 5 \\
\hline
\end{tabular}

The regression equations related to the brightness of nickel deposits as a function of the studied factors are as follows:

For nickel deposits in presence of SDS:

$$
\begin{gathered}
B r_{S D S}=-86.999+2.291 T+4.275 i+1.1089 C+16.833 p H+0.029 T i-5.775 \times \\
10^{-3} T C-0.3338 T p H-0.0178 i C-0.71 i p H-0.0654 C p H
\end{gathered}
$$


For nickel deposits in presence of PVP:

$$
\begin{gathered}
B r_{P V P}=207.287-2.1136 T+1.0827 i+0.01079 C-19.36 p H-0.02 T i+1.1515 \times 10^{-5} \\
T C+0.2328 T p H-2.4898 \times 10^{-4} i C-0.2966 i p H-2.085 \times 10^{-3} C p H
\end{gathered}
$$

The values of the brightness predicted from the regression equations are given in Table 2. The coefficients of determination $\left(\mathrm{R}^{2}\right)$ of $B r_{S D S}$ and $B r_{P V P}$ are, respectively, $98.98 \%$ and $99.38 \%$; these denote that only $1.02 \%$ and $0.62 \%$ of the total variability of both $B r_{S D S}$ and $B r_{P V P}$ are not explained by the regressors in the models.

\begin{tabular}{|c|c|c|c|c|c|c|c|c|c|c|}
\hline \multirow{3}{*}{$\begin{array}{c}\mathbf{R u} \\
\mathbf{n} \\
\mathbf{N}^{\circ}\end{array}$} & \multicolumn{4}{|c|}{$\begin{array}{c}\text { Coded values of } \\
\text { design factors }\end{array}$} & \multicolumn{6}{|c|}{ Brightness (GU) } \\
\hline & \multirow{2}{*}{$\mathbf{T}$} & \multirow{2}{*}{$\mathbf{i}$} & \multirow{2}{*}{$\mathbf{C}$} & \multirow{2}{*}{ pH } & \multicolumn{3}{|c|}{$B r_{S D S}$} & \multicolumn{3}{|c|}{$B r_{P V P}$} \\
\hline & & & & & Measured & Predicted & Residual & Measured & Predicted & Residual \\
\hline 1 & -1 & -1 & -1 & -1 & 41.85 & 41.245 & 0.605 & 89.37 & 88.961 & 0.408 \\
\hline 2 & 1 & -1 & -1 & -1 & 59.41 & 62.235 & -2.825 & 63.8 & 65.391 & -1.591 \\
\hline 3 & -1 & 1 & -1 & -1 & 66.97 & 68.86 & -1.89 & 85.4 & 84.444 & 0.955 \\
\hline 4 & 1 & 1 & -1 & -1 & 97.45 & 93.34 & 4.11 & 58.7 & 58.471 & 0.228 \\
\hline 5 & -1 & -1 & 1 & -1 & 68.04 & 67.232 & 0.8075 & 109.03 & 111.269 & -2.239 \\
\hline 6 & 1 & -1 & 1 & -1 & 86.17 & 84.757 & 1.4125 & 91.81 & 88.386 & 3.423 \\
\hline 7 & -1 & 1 & 1 & -1 & 89.61 & 89.132 & 0.4775 & 99.7 & 98.824 & 0.875 \\
\hline 8 & 1 & 1 & 1 & -1 & 107.45 & 110.147 & -2.6975 & 71.48 & 73.539 & -2.059 \\
\hline 9 & -1 & -1 & -1 & 1 & 39.58 & 38.945 & 0.635 & 66.95 & 65.171 & 1.778 \\
\hline 10 & 1 & -1 & -1 & 1 & 49 & 47.415 & 1.585 & 49.74 & 50.334 & -0.594 \\
\hline 11 & -1 & 1 & -1 & 1 & 53.01 & 52.36 & 0.65 & 51.58 & 54.721 & -3.141 \\
\hline 12 & 1 & 1 & -1 & 1 & 61.45 & 64.32 & -2.87 & 39.44 & 37.481 & 1.958 \\
\hline 13 & -1 & -1 & 1 & 1 & 56.34 & 58.387 & -2.0475 & 66.79 & 66.736 & 0.053 \\
\hline 14 & 1 & -1 & 1 & 1 & 63.22 & 63.392 & -0.1725 & 51.35 & 52.586 & -1.236 \\
\hline 15 & -1 & 1 & 1 & 1 & 66.85 & 66.087 & 0.7625 & 49.67 & 48.359 & 1.310 \\
\hline 16 & 1 & 1 & 1 & 1 & 76.04 & 74.582 & 1.4575 & 31.68 & 31.806 & -0.126 \\
\hline
\end{tabular}

Table 2. Design matrix with experimental and predicted responses.

Analysis of variance (ANOVA)

Analysis of variance of the nickel deposits brightness was made in order to analyze the effect of temperature, current density, concentration of surfactants and the $\mathrm{pH}$ of the solution on the brightness. Tables 3 and 4 show ANOVA results for $B r_{S D S}$ and $B r_{P V P}$, respectively. The analyses were carried out for a $5 \%$ significance level, i.e., for a $95 \%$ confidence level. In these tables, the degrees of freedom (DF), sum of squares (SC sq), mean square (MS), F-values, probabilities (Prob) and the contribution (Cont \%) of each factor and interactions are shown [33].

Fisher-values of $B r_{S D S}$ and $B r_{P V P}$ were 48.36 and 80.95, respectively. According to the Fisher-Snedecor statistical tables [34], the $F_{\text {models }}>F_{0.05}=4.74$, this means that both F-values are extremely significant. We also note that F-value of $B r_{P V P}>\mathrm{F}$-value of $B r_{S D S}$, indicating that $B r_{P V P}$ is more sensitive to the changes in the factors levels than $B r_{S D S}$. Furthermore, ANOVA tests show that all the studied factors are significant, i.e., they affect the brightness of nickel deposits. Concerning the interactions, only five are significant (two for SDS and three for 
PVP) among possible binary interactions. We also noted that the interactions $(T \times i)$ and $(T \times C)$ are not significant with both surfactants. Consequently, and after discarding the insignificant terms, the above regression equations (Eqs. 3 and 4) related to the brightness of nickel deposits could be reduced as follows. For nickel deposits in presence of SDS:

$$
B r_{S D S}=-86.999+2.291 T+4.275 i+1.1089 C+16.833 p H-0.3338 T p H-0.71 i p H
$$

For nickel deposits in presence of PVP:

$$
\begin{aligned}
B r_{P V P} & =207.287-2.1136 T+1.0827 i+0.01079 C-19.36 p H+0.2328 T p H \\
- & 2.4898 \times 10^{-4} i C-2.085 \times 10^{-3} C p H
\end{aligned}
$$

The values of $\mathrm{R}^{2}$ and Fisher test for the reduced models are as follows: $\mathrm{R}^{2}\left(B r_{\text {SDS }}\right)$ $=97.21 \%, \mathrm{R}^{2}\left(B r_{P V P}\right)=98.38 \%, \mathrm{~F}\left(B r_{S D S}\right)=52.32$ and $\mathrm{F}\left(B r_{P V P}\right)=96.69$.

The values of Fisher test and $\mathrm{R}$ squared of full and reduced models indicated that the derivative models are very satisfactory. We can then conclude that a multiple linear regression model with interaction is adequate and can be used as a prediction equation in this study.

Table 3. ANOVA results for the brightness of nickel deposit with SDS.

\begin{tabular}{|c|c|c|c|c|c|c|c|}
\hline Source & Sum of squares & DF & Mean squares & F-value & Prob & Cont \% & Remarks \\
\hline Model & 5581,0889 & 10 & 558,108 & 48,5606 & 0.0002 & & significant \\
\hline$T$ & 869,36522 & 1 & 869,365 & 75,6428 & 0.0003 & 15,41 & significant \\
\hline$i$ & 1505,8280 & 1 & 1505,82 & 131,020 & $<0.0001$ & 26,70 & significant \\
\hline$C$ & 1314,0625 & 1 & 1314,06 & 114,335 & 0.0001 & 23,30 & significant \\
\hline$p H$ & 1433,7582 & 1 & 1433,75 & 124,750 & 0.0001 & 25,42 & significant \\
\hline$T \times i$ & 12,1801 & 1 & 12,1801 & 1,05978 & 0.3505 & 0,216 & no significant \\
\hline$T \times C$ & 12,006225 & 1 & 12,0062 & 1,04465 & 0.3536 & 0,212 & no significant \\
\hline$T \times p H$ & 156,7504 & 1 & 156,750 & 13,6387 & 0.0141 & 2,779 & significant \\
\hline$i \times C$ & 32,661225 & 1 & 32,6612 & 2,84182 & 0.1527 & 0,579 & no significant \\
\hline $\boldsymbol{i} \times p H$ & 201,64 & 1 & 201,64 & 17,5445 & 0.0086 & 3,576 & significant \\
\hline$C \times p H$ & 42,837025 & 1 & 42,8370 & 3,72721 & 0.1114 & 0,759 & no significant \\
\hline Residual & 57,46515 & 5 & 11,4930 & & & 1,019 & \\
\hline Total & 5638,5541 & 15 & & & & 100 & \\
\hline
\end{tabular}

Table 4. ANOVA results for the brightness of nickel deposit with PVP.

\begin{tabular}{|c|c|c|c|c|c|c|c|}
\hline Source & Sum of squares & DF & Mean squares & F-value & Prob & Cont \% & Remarks \\
\hline Model & 7430.408 & 10 & 743.040891 & 80.95294 & $<0.0001$ & & significant \\
\hline$T$ & 1609.815 & 1 & 1609.81501 & 175.3864 & $<0.0001$ & 21.53 & significant \\
\hline$i$ & 639.96 & 1 & 639.963506 & 69.72285 & 0.0004 & 8.559 & significant \\
\hline$C$ & 276.64 & 1 & 276.640056 & 30.13942 & 0.0027 & 3.700 & significant \\
\hline$p H$ & 4293.19 & 1 & 4293.19801 & 467.7360 & $<0.0001$ & 57.42 & significant \\
\hline$T \times i$ & 5.7720 & 1 & 5.77200625 & 0.628849 & 0.4637 & 0.077 & no significant \\
\hline$T \times C$ & 0.4726 & 1 & 0.47265625 & 0.051495 & 0.8295 & 0.0063 & no significant \\
\hline$T \times p H$ & 76.256 & 1 & 76.2565563 & 8.30801 & 0.0345 & 1.0199 & significant \\
\hline$i \times C$ & 62.845 & 1 & 62.8452563 & 6.846875 & 0.0473 & 0.8405 & significant \\
\hline $\boldsymbol{i} \times p H$ & 35.194 & 1 & 35.1945563 & 3.83438 & 0.1075 & 0.4707 & no significant \\
\hline$C \times p H$ & 430.25 & 1 & 430.251306 & 46.8750 & 0.0010 & 5.7548 & significant \\
\hline Residual & 45.893 & 5 & 9.17867625 & & & 0.6138 & \\
\hline Total & 7476.302 & 15 & & & & 100 & \\
\hline
\end{tabular}


The last but one column of Tables (3 and 4) shows the factors contribution, indicating the degree of influence on the nickel brightness deposits. In the case of SDS, it is observed that the contributions of factors are in the order of magnitude $\approx 20 \pm 5 \%$, while the contribution of $\mathrm{pH}$ interaction with the current density and the bath temperature does not exceed $4 \%$. Concerning the nickel deposits produced in the presence of PVP, it seems clearly that $\mathrm{pH}$ affects considerably the brightness; its contribution is Cont $\approx 57.42 \%$, and this is due to the high sensitivity of the PVP adsorption with the $\mathrm{pH}$ [35]. The temperature, the current density, and the concentration of PVP are also significant, but their contributions are not the same. Besides the main effect of $\mathrm{pH}$, its interaction with the PVP concentration and the temperature is also significant. There is also a low contribution of the interaction between the current density and the concentration of PVP. It appears from the above results that the values of the factors contribution in the case of SDS are near, which is not the case with PVP; this finding explains the sensitivity of the brightness to the changes in the levels of factors in the case of PVP.

\section{Main effect}

The effect of a factor is defined as the change in response produced by a change in the level of the factor. Fig. 1 shows the main effects of the factors for $B r_{S D S}$ and $B r_{\text {pVP }}$. It can be seen from Fig. 1(a)-(d) that the temperature, the current density and the concentration of SDS have a positive effect on the brightness, whereas the $\mathrm{pH}$ has a negative effect. For $B r_{p v p}$, (Fig. 1(e)-(h)), the temperature, the current density and the $\mathrm{pH}$ of the solution have a negative effect, while PVP concentration has a positive effect.

Researchers have different opinions about what determine the brightness of the electrodeposits; grain size and/or their orientations along a direction promoting the reflection of the light. Many authors $[36,37]$ have reported that the brightness of electrodeposits increases remarkably with decreasing grain size. Furthermore, and according to the pattern presented by Dini [38], it is generally expected that the grain size decreases by either decreasing the temperature or increasing the current density and the concentration of added additives. Taking into account the above statements, we have projected the results of the main effect (Fig. 1), which link brightness versus factors, to the Dini pattern. It appears that the majority of plots (b), (c), (e) and (g) are consistent with the scheme of Dini. However, the effects of temperature in the case of SDS (Fig. 1(a)), and the effect of the current density in the case of PVP (Fig. 1(f)), are not in agreement with Dini pattern. It is known that the increase of the temperature favours from one part the kinetics driving forces [26] and, the surface diffusion [39] from another part. These two phenomena have opposite effects on the particle size. We conclude that increasing brightness as function of the temperature in the case of SDS is due to the domination of the kinetics driving force. Regarding the effect of the current density in the case of PVP, we believe that the interactions of PVP to the surface are reduced at high current densities, as mentioned recently by Hai et al. [40]. Concerning the $\mathrm{pH}$ effect, Fig. 1(c) and (h) shows that the brightness of deposits decreases with increasing $\mathrm{pH}$ values in both baths. This is expected since the 
increase of $\mathrm{pH}$ reduces the adsorbed amount of SDS [41] and PVP [35]. In addition, it is reported [42] that at $\mathrm{pH} \approx 5$, the amount of $\mathrm{PVP}$ adsorbed decreases compared to that of SDS, which could explain the greater slope of $\mathrm{pH}$ in the case of PVP (Fig. 1(h)).
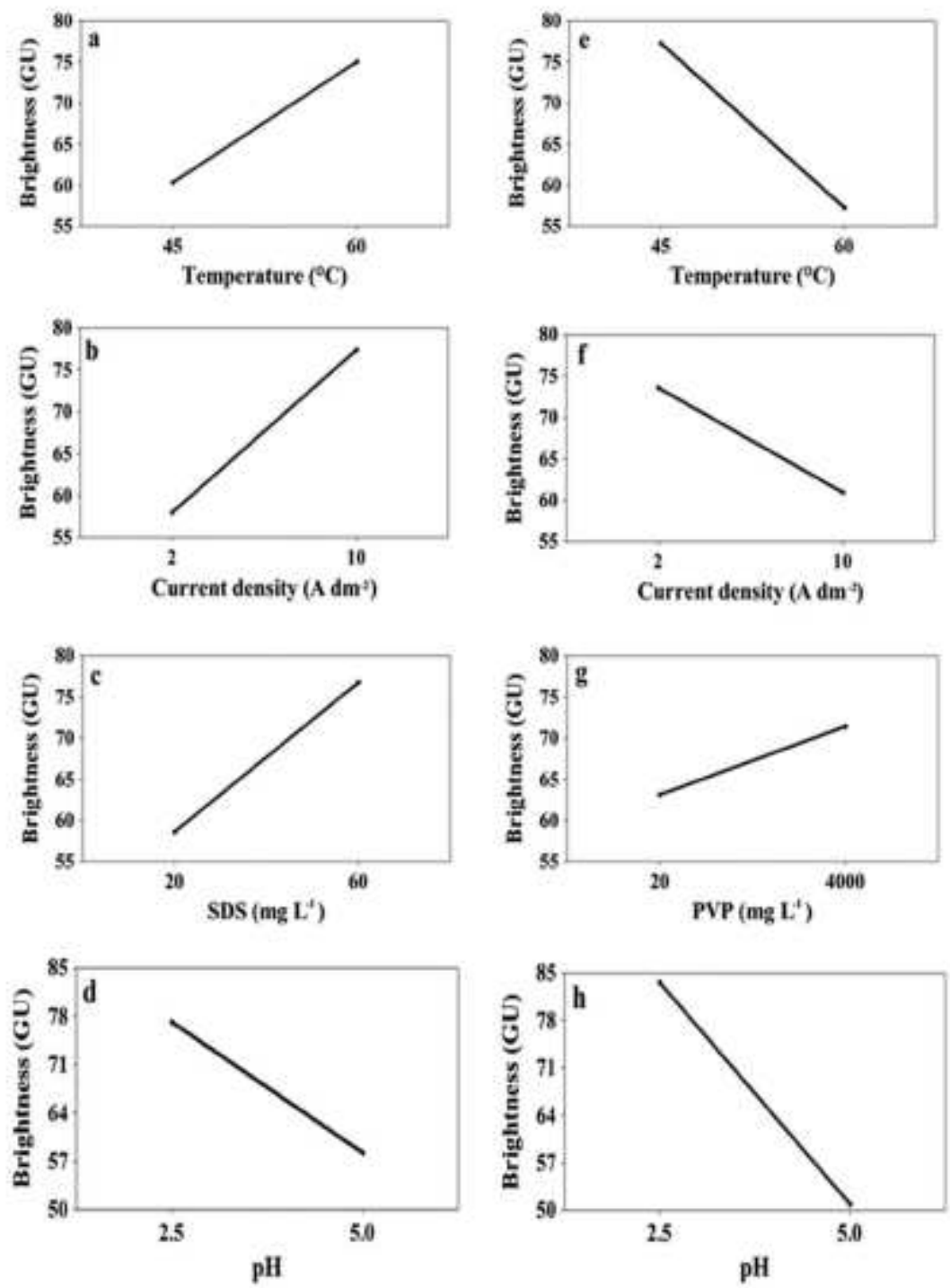

Figure 1. Main effect plots of nickel deposits in the presence of (a)-(d) SDS and (e)-(h) PVP.

As conclusion of this part, the brightness of nickel deposits in the presence of surfactants is not only dependent on the kinetics of discharge but also on the adsorption of surfactants and the diffusion of adatoms.

\section{Response surface plots}

Response surface plots are drawn in order to investigate the effects of factors interactions on the brightness (Fig. 2). Brightness is represented as function of two factors, holding the two other factors in the middle level.

Fig. 2(a) and (a') illustrates the response surface plots in case of $B r_{S D S}$. At higher $\mathrm{pH}$ values, the increase in both temperature (Fig. 2(a)) and current density 
(Fig. 2(a')) leads to a slight increase in $B r_{S D S}$, while for lower $\mathrm{pH}$ values, the growth of both temperature and current density conducts to a very significant increase in the response. So the best response surface could be obtained by the combination of the highest value of temperature and current density with the lowest $\mathrm{pH}$ value.
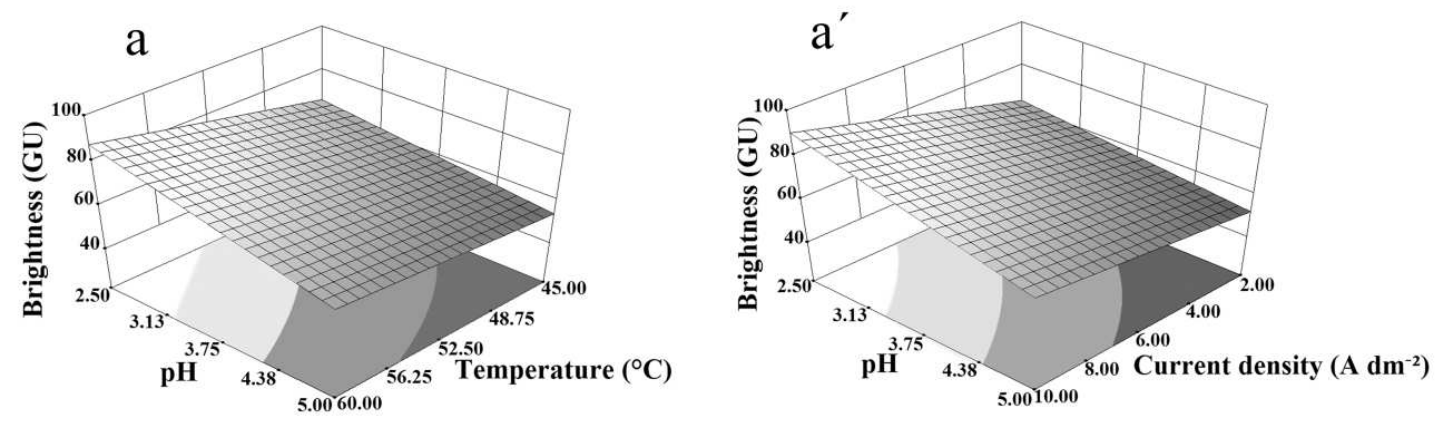

$\mathrm{b}$
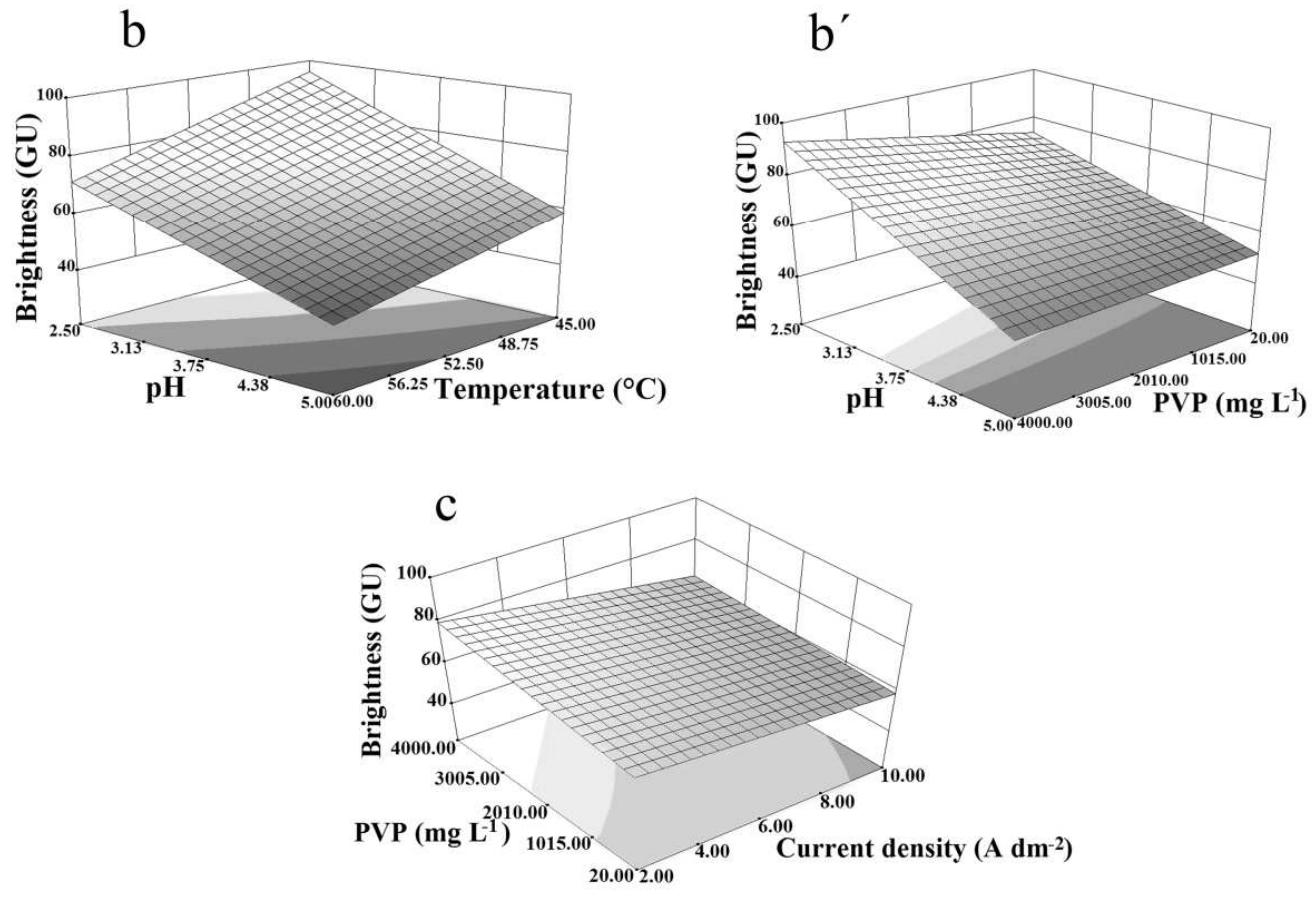

Figure 2. Three dimensional plots for significant interactions: [(a) and (a $\left.\left.a^{\prime}\right)\right]$ SDS, [(b), $\left(b^{\prime}\right)$ and (c)] PVP.

Fig. 2(b) and (b') highlights the effects of the factors interaction on $B r_{p V p}$. At higher $\mathrm{pH}$ values, the decreasing of temperature (Fig. 2(b)) or the increment in concentration of PVP (Fig. 2(b')) resulted in a slight increase in the response, but at lower $\mathrm{pH}$ values, the decreasing of temperature or the increasing of PVP concentration leads to an improve in the brightness. Thus, the best brightness could be obtained by the combination of the highest concentration of PVP with the lowest values of $\mathrm{pH}$ and temperature. The interaction between the current density and the concentration of PVP is represented in Fig. 2(c). It is shown that the interaction becomes important for the lowest values of current density and highest PVP concentration. It appears from the above results that the $\mathrm{pH}$ takes 
part in the majority of significant interactions, whereas the concentration of SDS falls outside in any significant interaction.

\section{Optimization of electrolysis parameters}

Optimization of electrolysis parameters for the nickel deposits brightness was carried out by a multiple response method called desirability function. We are interested in two approaches of optimization that we named "economic optimization" and "quality optimization". The first consists to find the maximum brightness by minimizing temperature, current density and the concentration of the surfactants, regardless the level of the $\mathrm{pH}$. In the second, we seek the maximum brightness in the whole range of the studied factors. The factors ranges defined for each optimization are summarized in Table 5, while the RSM optimization results are shown in Table 6.

Table 5. Goals and factors ranges for the brightness optimization; goal i (economic optimization) and goal ii (quality optimization).

\begin{tabular}{|c|c|c|c|c|c|}
\hline \multicolumn{2}{|l|}{ Factors } & Goal i & Goal ii & Lower limit & Upper limit \\
\hline \multicolumn{2}{|l|}{ Temperature $\left({ }^{\circ} \mathrm{C}\right)$} & Minimize & Is in range & 45 & 60 \\
\hline \multicolumn{2}{|c|}{ Current density $\left(\mathrm{A} \mathrm{dm}^{-2}\right)$} & Minimize & Is in range & 2 & 10 \\
\hline \multirow{2}{*}{$\begin{array}{l}\text { Surfactants concentration } \\
\left(\mathrm{mg} \mathrm{L}^{-1}\right)\end{array}$} & $\mathrm{C}_{\mathrm{SDS}}$ & Minimize & Is in range & 20 & 60 \\
\hline & $\mathrm{C}_{\mathrm{PVP}}$ & Minimize & Is in range & 20 & 4000 \\
\hline \multicolumn{2}{|l|}{$\mathrm{pH}$} & Is in range & Is in range & 2.5 & 5 \\
\hline \multirow{2}{*}{ Brightness (GU) } & $B r_{3 D S}$ & \multirow{2}{*}{\multicolumn{2}{|c|}{ Maximize }} & 39.58 & 107.45 \\
\hline & $B r_{e Y p}$ & & & 31.68 & 109.03 \\
\hline
\end{tabular}

Table 6. Optimization results.

\begin{tabular}{|c|c|c|c|c|c|c|}
\hline Optimization & $\begin{array}{c}\text { Temperature } \\
\left({ }^{\circ} \mathbf{C}\right)\end{array}$ & $\begin{array}{c}\text { Current density } \\
\left(\mathbf{A ~ d m}^{-2}\right)\end{array}$ & $\begin{array}{c}\text { Concentration } \\
\left(\mathbf{m g ~ L}^{-1}\right)\end{array}$ & $\mathbf{p H}$ & $\begin{array}{c}\boldsymbol{B r}_{\text {SDS }} \\
(\mathbf{G U})\end{array}$ & $\begin{array}{c}\boldsymbol{B r}_{\text {PVP }} \\
(\mathbf{G U})\end{array}$ \\
\hline \multirow{2}{*}{ Economic } & 55.11 & 7.98 & 20 & 2.5 & 77.79 & \\
\cline { 2 - 7 } & 45.00 & 2.00 & 20 & 2.5 & & 88.962 \\
\hline \multirow{2}{*}{ Quality } & 60 & 10 & 60 & 2.5 & 110.14 & \\
\cline { 2 - 7 } & 45 & 2 & 4000 & 2.5 & & 111.27 \\
\hline
\end{tabular}

In the case of economic optimization, the best calculated brightness of nickel deposits with SDS, generated among 31 optimums points, is $B r_{S D S}=77.79 \mathrm{GU}$. It is achieved at $\mathrm{T}=55.11{ }^{\circ} \mathrm{C}, \mathrm{i}=7.98 \mathrm{~A} \mathrm{dm}^{-2}$, for the SDS concentration of 20 $\mathrm{mg} \mathrm{L}^{-1}$, this corresponds to a value of desirability equals 0.729 . The best calculated brightness of nickel deposits with PVP, generated among 34 optimums points, is $B r_{P V P}=88.9619 \mathrm{GU}$. It is reached at $\mathrm{T}=45^{\circ} \mathrm{C}, \mathrm{i}=2 \mathrm{~A} \mathrm{dm}^{-2}$, for the PVP concentration of $20 \mathrm{mg} \mathrm{L}^{-1}$, and with 0.915 desirability. The values of desirability show that the PVP is more appropriate in strategy of economic optimization.

In the case of the quality optimization, the results show that with both surfactants, we reach the maximum brightness values very close, which are $(110.147 \mathrm{GU})$ for the SDS and $(111.269 \mathrm{GU})$ for the PVP, and the value of desirability equals unity. The values of factors corresponding to these brightness values are the same as those by which we obtained the maximum experimental 
brightness. This indicates once again the concordance between the experimental results and the derivatives model.

Comparison between the two optimization strategies gives a small advantage to the SDS- containing bath when the maximum of brightness is required. But the bath with PVP wins if an environment-friendly industry is adopted. Thus, PVP could efficiently and eco-friendly substitute SDS as an additive of nickel electroplating.
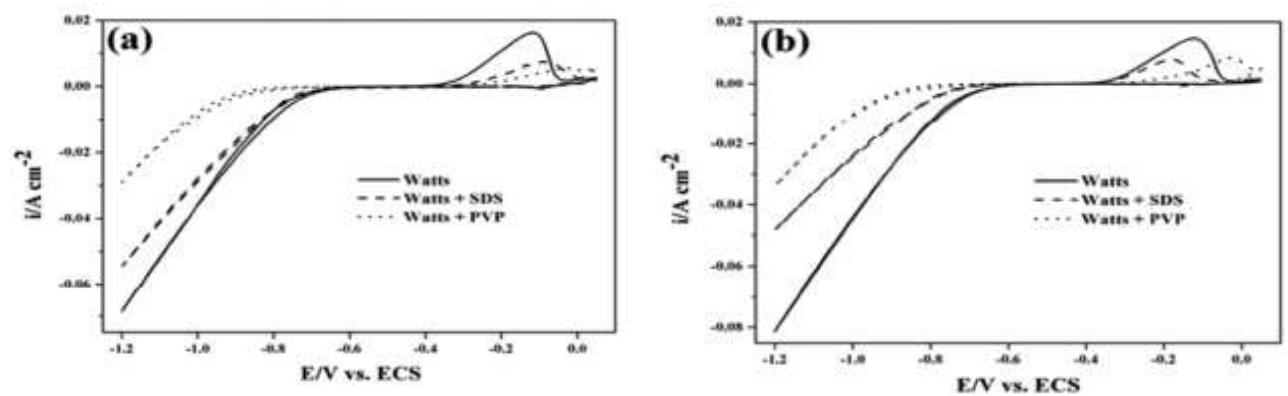

Figure 3. Cyclic voltammograms of the Watts bath (solid line), Watts $+20 \mathrm{mg} \mathrm{L}^{-1} \mathrm{SDS}$ (dashed line) and Watts $+20 \mathrm{mg} \mathrm{L}^{-1} \mathrm{PVP}$ (dotted line), at different temperatures: (a) 45 ${ }^{\circ} \mathrm{C}$, (b) $60{ }^{\circ} \mathrm{C}, \mathrm{pH}=2.5$.

\section{Polarization study}

In order to evaluate the electrochemical behaviour of baths and deposits, we achieved cyclic voltammograms and corrosion plots.

Table 7. Brightness values of deposits performed at the electrolysis parameters values of voltammograms.

\begin{tabular}{|c|c|c|c|c|c|}
\hline Deposits & $\begin{array}{c}\text { Temperature } \\
\left({ }^{\circ} \mathbf{C}\right)\end{array}$ & $\begin{array}{c}\text { Current density } \\
\left(\mathbf{A ~ d ~ d ~}^{-2}\right)\end{array}$ & $\begin{array}{c}\text { Concentration } \\
\left(\mathbf{m g ~ L}^{-\mathbf{1}}\right)\end{array}$ & $\mathbf{p H}$ & $\begin{array}{c}\text { Brightness } \\
(\mathbf{G U})\end{array}$ \\
\hline \multirow{2}{*}{ Ni with SDS } & 45 & 5.36 & 20 & 2.5 & 52.86 \\
\cline { 2 - 6 } & 60 & 4.77 & 20 & 2.5 & 73 \\
\hline \multirow{2}{*}{ Ni with PVP } & 45 & 2.89 & 20 & 2.5 & 88.45 \\
\cline { 2 - 7 } & 60 & 3.33 & 20 & 2.5 & 64.24 \\
\hline
\end{tabular}

\section{Cyclic voltammetry}

Fig. 3(a) and (b) shows cyclic voltammograms obtained on the copper substrate during nickel electrodeposition, at temperatures of $45^{\circ} \mathrm{C}$ and $60{ }^{\circ} \mathrm{C}$, respectively. Typical voltammograms related to Watts bath are represented by solid lines. They show that the reduction of nickel ions starts at about $-0.71 \mathrm{~V}$ leading to the reduction of nickel ions to metallic nickel. The curves represented by dashed and dotted lines, illustrate the effect exerted by SDS and PVP, respectively. It's clearly shown that both SDS and PVP inhibit the reduction reaction of nickel ions; this effect is more marked with PVP at both temperatures. Table 7 gives the values of the deposits brightness performed with the same electrolysis parameters values of the voltammograms. In the case of SDS, the increase in temperature leads to a reduction of the cathodic current density, that is to say, there was a phenomenon of inhibition; in the other hand, the brightness increases with temperature. However, in the case of PVP, the decrease in temperature favours the inhibition of the current density and also the brightness of the deposit. This 
indicates that the brightness and the inhibition are well linked, and the two phenomena are directly proportional.

\section{Effect of SDS and PVP on corrosion resistance of coatings}

Fig. 4 presents the potentiostatic polarization curves for nickel coatings obtained from Watts baths (with and without surfactants). In order to understand the behaviour of deposits towards corrosion, Tafel plots were used to determine the corrosion parameters, such as corrosion current density ( $\left.i_{\text {corr }}\right)$ and corrosion potential $\left(\mathrm{E}_{\text {corr }}\right)$.

The experimental results (Table 8) indicated that the nickel coatings elaborated from Watts bath with SDS and PVP have corrosion current density lower than that prepared from Watts bath without additives. So the addition of surfactants conducts to a decrease in the rate of corrosion. Mohanty et al. [4] found analogue results with SDS, but from sulfate baths. The decreasing of the corrosion potential in the presence of surfactants, by about $10 \mathrm{mV}$, shows that their inhibition is of cathodic type. Thus, the reduction of the corrosion current density of the deposits obtained in the presence of surfactants indicates enhancement of their electrochemical properties versus those achieved without additives.

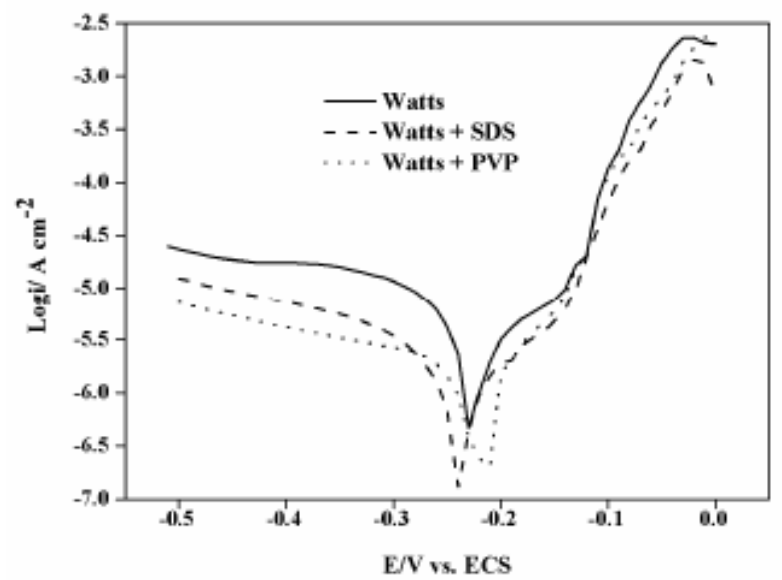

Figure 4. Dynamic polarization behaviour of nickel deposits obtained from different baths, scan rate, $5 \mathrm{mVs}^{-1}$.

Table 8. Corrosion parameters of nickel deposits obtained from different baths.

\begin{tabular}{|c|c|c|c|}
\hline Corrosion parameter & Watts & Watts + SDS & Watts + PVP \\
\hline$i_{\text {corr }}\left(\mathrm{A} \mathrm{cm}^{-2}\right)$ & $3.007 \times 10^{-6}$ & $1.985 \times 10^{-6}$ & $1.472 \times 10^{-6}$ \\
\hline$E_{\text {corr }}(\mathrm{V})$ & -0.1900 & -0.2013 & -0.2002 \\
\hline Corrosion rate $\left(\mathrm{mm}\right.$ year $\left.^{-1}\right)$ & 0.032 & 0.021 & 0.015 \\
\hline Efficiency protection & & $0.34 \%$ & $0.51 \%$ \\
\hline
\end{tabular}

\section{Conclusions}

The influence of electrolysis parameters on the nickel deposits brightness in the presence of SDS and PVP were explored using RSM. The linear regression model with interactions provided excellent relationships between the design factors and the brightness. 
Based on the analysis of variance tools, all studied factors were found significant and the brightness of deposits from baths containing PVP was more sensitive to the changes in the levels of factors than that relating to the SDS. The $\mathrm{pH}$ influenced principally the brightness of nickel deposits from bath containing PVP and takes part in the majority of significant interactions.

The brightness of deposits is not only dependent on the electrochemical kinetics but also on the adsorption of surfactants and the diffusion of adatoms. The voltammetric study showed that both SDS and PVP inhibit the nickel electrodeposition.

The comparative analysis of the brightness and the cyclic voltammetry results indicated that the inhibition and the brightness are well linked and directly proportional. Besides, the corrosion resistance of the nickel coatings was slightly improved, especially with PVP.

As a final point, PVP, which is less expensive, and non-toxic, could efficiently and eco-friendly substitute SDS as an additive of nickel electroplating. Therefore, these results provide promising perspectives for the use of PVP for future commercial applications.

\section{Acknowledgements}

The financial support by the General Directorate for Scientific Research and Technological Development, Algeria (PNR project no. 13-u24-4029) is greatly acknowledged.

\section{References}

1. Chung CK, Chang WT, Chen CF, et al. Mater Lett. 2011;65:416-419

2. di Bari GA. In: Electrodeposition of nickel. Schlesinger M, Paunovic M, editors. New Jersey: Wiley and Sons, Inc; 2010. Vol 55, p.79.

3. Rudnik E, Wojnicki M, Włoch G. Surf Coat Technol. 2012;207:375-388.

4. Mohanty US, Tripathy BC, Das SC, et al. Hydrometallurgy. 2009;100:6064.

5. Jing LU, Qi-Hua Y, Zhao Z. Trans Nonferrous Met Soc China. 2010;20:97101.

6. Sen R, Bhattacharya S, Das S, et al. J Alloys Compd. 2010;489:650-658.

7. Sabri M, Sarabi AA, Kondelo SMN. Mater Chem Phys. 2012;136:566-569.

8. Ghavami RK, Rafiei Z. J Power Sources. 2006;162:893-899.

9. Kim S, Jang JH, Lee JS, et al. Electrochim Acta. 2007;52:5258-5265.

10. McFadden SX, Mukherjee AK. Mater Sci Eng A. 2005;395:265-268.

11. Dennis JK, Such TE. Nickel and chromium plating. 3rd ed. Cambridge: Woodhead Publ Ltd; 1993.

12. Godon A, Creus J, Feaugas X, et al. Mater Charact. 2011;62:164-173.

13. Mohanty US, Tripathy BC, Das SC, et al. Metall Mater Trans B. 2005;36:737-741

14. Wang P, Gan T, Zhang J, et al. J Mol Liq. 2013;177:129-132.

15. Khaled MM. Arab J Sci Eng. 2010;35:29-39. 
16. Gurten AA, Erbil M, Kayakırılmaz K. Cem Concr Compos. 2005;27:802808.

17. Jianguo Y, Lin W, Otieno-Alegoi V, et al. Corros Sci. 1995;37:975-985.

18. Li Q, Zeng G-Z, Zhao W-F, et al. Synth Met. 2010;160:200-202.

19. Bayrakdar E, Altınçekiç TG, Öksüzömer F. Fuel Process Technol. 2013;110:167-175.

20. Chen Z, Tang Y, Zhang L, et al. Electrochim Acta. 2006;51:5870-5875.

21. Ghasemi S, Mousavi MF, Shamsipur M. Electrochim Acta. 2007;53:459467.

22. Nekouie RK, Rashchi F, Joda NN. Powder Technol. 2013;237:554-561.

23. Song Y-J, Han S-B, Park K-W. Mater Lett. 2010;64:1981-1984.

24. Vasilache V, Gutt S, Gutt G, et al. Rom J Chem. 2009;54:243-246.

25. Li J-M, Cai C, Song L-X, et al. Trans Nonferrous Met Soc China. 2013;23: 2300-2306.

26. Rashidi AM, Amadeh A. J Mater Sci Technol. 2010;26:82-86.

27. Abd El Wahab SM, Abd El Halim MM, Abd El Rehim SS, et al. Surf Coat Technol. 1986;29:313-324

28. Yuan X, Sun D, Yu H, et al. Surf Coat Technol. 2007;202:294-300.

29. Santana RAC, Prasad S, Moura ES, et al. Mater Sci. 2007;42:2290-2296.

30. Baib A, Hu C-C. Electrochim Acta. 2005;50:1335-1345.

31. Hu C-C, Baib A. J Appl Electrochem. 2001;31:565-572.

32. Poroch-Seritan MP, Gutt S, Gutt G, et al. Chem Eng Res Des. 2011;89:136147.

33. Aouici1 H, Yallese MA, Fnides B, et al. J Mech Sci Technol. 2011;25:2843-2851.

34. Brereton RG. Chemometrics: Data analysis for the laboratory and chemical plant. England: John Wiley and Sons Limited; 2003.

35. Lakhwani S, Rahaman MN. J Mater Sci. 1999;34: 3909-3912.

36. Sezer E, Ustamehmetoglu B, Katirci R. Surf Coat Technol. 2012;213:253263.

37. Stoychev DS, Tomov I, Vitanova I, et al. Surf Technol. 1978;7:433-441.

38. Dini JW. Electrodeposition: The Materials Science of Coatings and Substrates. Westwood, New Jersey: Noyes publications; 1993.

39. Song Y-J, Oh J-K, Park K-W. Nanotechnology. 2008;19:355602.

40. Hai NTM, Furrer J, Stricker F, et al. J Electrochem Soc. 2013;160:31163125.

41. Li N, Thomas RK, Rennie AR. J Colloid Interface Sci. 2012;378:152-158.

42. Ma C, Li C. J Colloid Interface Sci. 1989;131:485-492. 